\title{
EFEITOS DA MUSICOTERAPIA NA COMUNICAÇÃO, SOCIALIZAÇÃO E IMAGINAÇÃO EM CRIANÇAS COM PERTURBAÇÃO DO ESPECTRO DO AUTISMO: UM ESTUDO DE CASO EM REBORDOSA - PORTUGAL
}

\author{
Lucília Maria Dias Teixeira iD1 e Patrícia Raquel Silva Fernandes iD2
}

\section{Resumo}

No estudo apresentado propomo-nos aceder à melhor compreensão da existência de benefícios da música como intervenção terapêutica pretendendo explorar os efeitos desta em crianças com Perturbação do Espectro do Autismo (PEA) referindo e sustentando a ideia que trará benefícios na comunicação, socialização e imaginação destas crianças que apresentam défices específicos na comunicação, interação social, comportamentos estereotipados, dificuldade em usar a imaginação e resistência à alteração das rotinas e que a musicoterapia assume um papel de destaque na intervenção destas crianças. A metodologia utilizada foi de natureza qualitativa, com recurso a um estudo de caso de uma criança com PEA que frequenta a Unidade de Ensino Estruturado da Escola Básica n. ${ }^{\circ} 1$ de Rebordosa, concelho de Paredes em Portugal e sessões de musicoterapia duas vezes por semana. Neste estudo, participaram elementos da família (pais), docentes (Professora de Educação Especial e Professora Titular de Turma) e técnicos especializados (Musicoterapeutas). Os instrumentos utilizados nesta investigação para recolha de dados foram a entrevista aos pais e ao musicoterapeuta da Associação Portuguesa para as Perturbações do Desenvolvimento e Autismo (APPDA-Norte) e a observação direta da criança em dez sessões de musicoterapia com registos escritos. Os resultados permitem-nos concluir que a musicoterapia assume um papel fulcral como facilitador da comunicação, socialização e imaginação de crianças com PEA, desenvolvendo capacidades de autorregulação emocional, social e impulsionando a expressão harmoniosa das suas emoções contribuindo para o seu bem-estar e desenvolvimento cognitivo. A música é linguagem e serve de canal de comunicação entre a criança e o mundo que a rodeia aproximando-a dos seus pares.

Palavras-chave: Música; Musicoterapia; Perturbação do Espectro do Autismo.

\section{EFFECTS OF MUSIC THERAPY IN COMMUNICATION, SOCIALIZATION AND IMAGINATION IN CHILDREN WITH AUTISTIC SPECTRUM DISORDERS: UM CASE STUDY EM REBORDOSA - PORTUGAL}

\section{Abstract}

In the study presented we propose to access a better understanding of the existence of benefits of music as a therapeutic intervention intending to explore its effects on

\footnotetext{
${ }^{1}$ Mestre em Ensino do 10 Ciclo de Ensino Básico pela Universidade de Trás-os-Montes e Alto Douro - Portugal. Professora Educação Especial no Ministério da Educação, Portugal.

${ }^{2}$ Doutoramento em Estudos da Criança, especialidade Educação Especial pela Universidade do Minho, Braga, Portugal. Professora Adjunta e Coordenadora do Mestrado Educação Especial, Domínio Cognitivo e Motor Bem-Estar, Saúde e Envelhecimento.
}

(9) (1) Perspectivas em Diálogo, Naviraí, v. 8, n. 16, p. 149-163, jan./abr. 2021. 
children with Autism Spectrum Disorder (ASD) referring and supporting the idea that will bring benefits in communication, socialization and imagination of these children who have specific deficits in communication, social interaction, stereotyped behaviors, difficulty in using the imagination and resistance to change routines and that music therapy assumes a prominent role in the intervention of these children. The methodology used was of a qualitative nature, with recourse to a case study of a child with ADP who attends the Structured Teaching Unit of the Escola Básica n. ${ }^{\circ} 1$ de Rebordosa, municipality of Paredes in Portugal, and music therapy sessions twice a week. This study was attended by family members (parents), teachers (Special Education Teacher and Class Teacher) and specialized technicians (Music Therapists). The instruments used in this research to collect data were the interview with parents and the music therapist of the Portuguese Association for Developmental Disorders and Autism (APPDA-Norte) and the direct observation of the child in ten music therapy sessions with written records. The results allow us to conclude that music therapy assumes a central role as a facilitator of communication, socialization and imagination of children with ADP, developing emotional and social self-regulation capabilities and boosting the harmonious expression of their emotions contributing to their well-being and cognitive development. Music is language and serves as a channel of communication between children and the world around them, bringing them closer to their peers.

Keywords: Music; music therapy; Autistic Spectrum Disorders.

\section{Introdução}

A música acompanha o ser humano na sua trajetória existencial, pois sua relação com a música é tão antiga como a sua própria existência contribuindo para a sua identidade cultural e artística, usada como veículo de expressão de sentimentos nas mais variadas formas. É parte integrante das atividades realizadas pela humanidade e usada no cuidado em saúde. A música possui ordem, harmonia e equilíbrio e chega ao nosso ouvido sobre a forma de vibração, permitindo que o nosso cérebro a interprete e a associe ao bem-estar, como algo organizado e agradável (MATOSO; OLIVEIRA, 2017). A música permite exprimir emoções, mobilizar processos cognitivos complexos como atenção, memória, controle de impulsos, execução e controle de ações motoras (SAMPAIO; LOUREIRO; GOMES, 2015).

A capacidade inata do ser humano responder a estímulos musicais abre caminho à comunicação através da música e dos sons musicais. Os sons e a música têm uma forte componente biológica que também permitem uma ligação muito especial com o indivíduo, visto que todo o corpo humano funciona a um determinado ritmo, desde o batimento cardíaco, ainda dentro do ventre materno, ao som produzido pelos seus passos ao caminhar e à sua própria voz. (BRUSCIA, 2000; MONTEIRO, 2016). Assim, de acordo com Cunha (2014) e Monteiro (2016), podemos falar da existência de uma linguagem musical universal capaz de ultrapassar barreiras culturais, cognitivas e emocionais, abrindo caminhos na comunicação de todos os seres humanos através da criação, interpretação, escuta e improvisação musical. A música é vista como um veículo de comunicação de tal forma importante que se considera um estímulo para conservar a saúde, felicidade e conforto, a prática 
musical em grupo, constitui um veículo motor de acesso à comunicação entre pessoas (FERNANDES, 2017).

De acordo com Ferreira (2012), a música é considerada uma arte porque permite satisfazer o instinto criador da criança, desenvolvendo a capacidade de apreciar o belo, enriquecendo a vida. Ao brincar com sons e ritmos a criança começa a experimentar e a criar, expressando-se de forma individual, rica e criativa.

A música é vista como prática cultural e humana, essencial na aprendizagem permitindo a auto expressão das emoções e tem um grande impacto na educação, com especial realce na educação de crianças e jovens com Necessidades Educativas Especiais (NEE) (FERNANDES, 2017). O estímulo musical representa um canal alternativo para a comunicação quando estas crianças e jovens com NEE não respondem aos canais de comunicação normais, pode até, quando associada ao movimento rítmico, contribuir para a iniciação da fala e resposta motora (RUUD,1990; FERNANDES, 2017).

Do interesse em usar a música e os sons para melhorar o bem-estar do ser humano, surgiu a musicoterapia (BRUSCIA, 2000; MONTEIRO, 2016). A musicoterapia é a utilização da música e dos seus elementos, som, ritmo, melodia e harmonia por um terapeuta qualificado e pretende facilitar e promover a comunicação, a aprendizagem, a relação, a expressão e a organização contribuindo para o desenvolvimento das capacidades de comunicação, expressão e coordenação motora, permitindo dar resposta a nível emocional, cognitivo, social e físico de cada indivíduo (WOLD FEDERETION OF MUSIC THERAPY, 2008; MONTEIRO, 2016) e permite alcançar uma melhor qualidade de vida, recorrendo à prevenção, reabilitação ou tratamento (FERNANDES, 2017). A musicoterapia é a utilização da música e dos seus elementos, som, ritmo, melodia e harmonia no tratamento de distúrbios de natureza orgânica, psíquica, emocional e cognitiva (FRAGA; ALLGAYER; KRUG, 2017) e deve primar por um atendimento humanizado, acolhedor e integral à saúde do indivíduo (FREITAS; GUIMARÃES; USTCH; SOARES; NETO, 2017). Deve promover e estabelecer comunicação e interação entre o terapeuta, o paciente e a música promovendo a criatividade e espontaneidade e possibilitar a comunicação e expressão emocional (DE VRIES, 2015).

A musicoterapeuta integra uma equipe multidisciplinar formada por diversos profissionais. Quando é aplicada no meio escolar tem como objetivo ampliar a experiência musical e influenciar a capacidade de aprendizagem, melhorando a motivação e empenho dos alunos, permitindo que estes, através de formas expressivas melódicas e rítmicas, estruturem a comunicação de pensamentos e emoções. Durante as atividades desenvolvidas, dá-se ênfase à improvisação musical, visto que desta forma há mais interação e permite entender os sentimentos e emoções mais profundos do paciente. (WHEELER, 2012; MONTEIRO, 2016). Em contexto escolar é uma mais-valia, pois as crianças encaram esta atividade como algo lúdico e divertido (WIGRAM; PEDERSEN, 2002; MONTEIRO, 2016).

Em crianças e jovens com PEA, a música assume um papel fundamental como meio de comunicação, uma vez que estes possuem aptidões musicais e talentos acústicos fora do normal que é esperado (FERNANDES, 2017).

De acordo com o Manual Diagnóstico e Estatístico de Transtornos Mentais (DSM-5, 2013), organizado pela Associação Americana de Psiquiatria, a Perturbação do Espectro do Autismo (PEA) é um distúrbio neuro comportamental com origem em perturbações do sistema nervoso central que afeta o normal desenvolvimento da 
criança. A palavra autismo tem origem do grego "autos" que significa o próprio/eu e do sufixo "ismo" que transmite a ideia de ação ou estado (FERNANDES, 2017), ou seja, representa o estado de alguém que tendencialmente se alheia da realidade exterior e se concentra em si próprio. É uma perturbação que se prolonga por toda a vida e evolui (FPDA, 2017), porém, um diagnóstico precoce possibilita melhorias significativas.

As crianças com PEA apresentam défices significativos do comportamento que consiste numa Tríade de Incapacidades: comunicação, socialização e imaginação (PLIMLEY; BOWEN; MORGAN, 2007; FOLGADO, 2013).

Fernandes (2017) considera que os alunos com PEA apresentam défices significativos do comportamento que consiste numa Tríade de Incapacidades:

- Comunicação: manifesta-se na dificuldade em compreender a necessidade de estabelecer um diálogo com o outro, quando comunicam revelam dificuldades significativas em falar sobre sentimentos, pensamentos, emoções, ideias ou crenças do outro. Usam poucos gestos, mímica ou variação de tom de voz, usam um tom monocórdico para se exprimir.

- Socialização: manifesta-se na aparente indiferença em relação aos outros e isolamento face àquilo que os rodeia.

- Imaginação: manifesta-se na incapacidade para participar em jogos e brincadeiras com os pares, não brincam criativamente e chegam a passar horas a explorar um objeto específico.

Esta tríade reúne as características que permitem elaborar o diagnóstico de PEA, apesar de cada criança possuir características próprias que a distinguem de outras crianças com a mesma perturbação. A PEA é uma perturbação que se prolonga por toda a vida e evolui (FPDA, 2017), porém, um diagnóstico precoce possibilita melhorias significativas das crianças portadoras desta perturbação.

Neste contexto, a musicoterapia surge como uma nova porta de entrada para o mundo autista (HERDY; CARMO, 2016) e a implementação dos objetivos em crianças com PEA tem resultados comprovados na área da comunicação, comportamento social, desenvolvimento intelectual e regulação corporal (DE VRIES, 2015). Segundo Simpson (2013), estes indivíduos criam uma relação muito especial com a música, atendendo ao facto de permanecerem mais tempo envolvidos na atividade, contribuindo para a trabalhar a capacidade de atenção dirigida.

A musicoterapia assume então um papel de destaque na intervenção destas crianças, uma vez que se verifica melhorias na comunicação verbal e não-verbal, autor regulação emocional e social, atenção conjunta e capacidade na seleção de estímulos externos (LAGASSE, 2014). A música pode ser uma força motivadora na integração da criança com PEA, tendo em vista a possibilidade de trabalhar objetivos terapêuticos e impulsionar a expressão das suas emoções que são representativas dos seus traços de personalidade (EREN, 2015), estabelecendo um novo canal de comunicação (HERDY; CARMO, 2016). A música é responsável pelo despoletar de emoções através do ritmo, altura das notas, tempo e intensidade, através da música, são expressas diversas emoções, tais como, felicidade, entusiasmo, tristeza, raiva e medo (DE VRIES, 2015). Através da música pode ser trabalhada a ansiedade, característica comum em crianças com PEA, que se sentem desconfortáveis com situações novas ou desconhecidas, necessitando estabelecer rotinas e atividades estruturadas, pois a música apresenta uma pulsação, um ritmo e uma cadência 
melódica que permite prever o som que vem de seguida ou quando vai terminar (KIM; WIGRAM; GOLD, 2009; MONTEIRO, 2016).

A prática da musicoterapia baseada na produção musical ativa e improvisada é bem-sucedida em crianças com PEA (BUNT; STIEGE, 2014), pois parte da análise das características musicais da criança no sentido de aceitar as suas idiossincrasias sonoras, dando ênfase à improvisação empática (CASTRO, 2016), pode contribuir para o bem-estar físico e emocional destas crianças e melhorar a comunicação verbal, atenção dirigida, comportamento social, expressão emocional e encorajar o contato ocular (DE VRIES, 2015).

De acordo com o estudo de Monteiro (2016), Castro (2016) e Fernandes (2017), a expectativa é que através da musicoterapia as crianças com PEA desenvolvam a comunicação, socialização e imaginação contribuindo para o desenvolvimento integral e harmonioso, atenuando as diferenças e barreiras no sentido de possibilitar a boa integração social, comportamental, cognitiva e emocional destas crianças.

O objetivo principal deste trabalho é perceber como a musicoterapia poderá promover o desenvolvimento da comunicação, socialização e imaginação das crianças com Perturbação do Espectro do Autismo. Perceber como é que a música poderá contribuir para a autonomia, autoestima, e interação com os seus pares e se com esta intervenção se verificam mudanças comportamentais, sociais e afetivas, assim como poderá contribuir para o desenvolvimento cognitivo destas crianças.

\section{Método}

\subsection{Participantes}

Na presente investigação centramo-nos na abordagem de um estudo de caso de um aluno que frequenta o terceiro ano de escolaridade na Unidade de Ensino Estruturado (UEE) da Escola Básica n. ${ }^{\circ} 1$ de Rebordosa, pertencente ao Agrupamento de Escolas de Vilela, no conselho de Paredes, em Portugal no referido estudo de caso centramo-nos numa criança com PEA.

$O$ aluno é identificado como $A$, o qual foi diagnosticado com PEA em maio de 2011 e está desde essa data tendo consultas de pedopsiquiatria no Centro Hospitalar do Porto - Hospital Maria Pia. Usufrui de consultas de Terapia da Fala e Terapia Ocupacional do Instituto do Desenvolvimento (ID) e serviço de psicologia na UEE. A referida UEE dispõe ainda de sessões de Musicoterapia, Hipoterapia, Hidroterapia, sala de Snoezelen e Psicomotricidade. O A. é uma criança meiga, muito dócil e afável, com constrangimentos ao nível do desenvolvimento emocional, interações sociais, tolerância à frustração e dificuldades na comunicação. O A. não verbaliza, utiliza sons vocálicos sem sentido e alguns gestos quando pretende ajuda de um adulto. Como forma de comunicar utiliza a simbologia PECS (Picture Exchange Communication System) e o programa "Let me talk" no tablet. Revela ainda dificuldades em estabelecer o contato ocular e na observação de objetos ou de acontecimentos com intencionalidade, verificando-se ausência relativamente ao que o rodeia. Revela pouco interesse pelas tarefas que lhe são propostas, mas aceita a ordem do adulto e executa-as com orientação. Capta estímulos auditivos sobretudo da música que o mantém calmo e atento, nas sessões de musicoterapia demonstra-se muito concentrado e interessado em aprender a imitar os sons produzidos por um 
instrumento ou na imitação de gestos de canções. A nível da motricidade fina apresenta dificuldades na coordenação e movimentos finos. É autónomo nas ações direcionadas para autocuidados, tais como, idas à casa de banho e alimentação, necessitando apenas de monitorização. Não reage aos estímulos dos pares, nem procura o contato destes, necessitando de estimulação para o efeito.

Numa fase inicial, recorremos à análise dos documentos considerados pertinentes que constam no processo individual do aluno e que foram cedidos, sob autorização prévia, pela docente titular de turma e pela docente de educação especial, informação registada resultante de encontros informais e numa fase posterior, observação direta com recurso a registos numa grelha constituída por alguns itens retirados e adaptados de Improvisational Assessment Ptofiles (BRUSCIA, 2000), aquando das observações nas dez sessões de musicoterapia.

Para esta investigação foi ainda relevante realizar uma entrevista aos pais do aluno de modo a conhecer o indivíduo em estudo e ao musicoterapeuta da Associação Portuguesa para as Perturbações do Desenvolvimento e Autismo-Norte (APPDANorte), por ser um elemento de extrema relevância face à sua experiência com crianças e jovens com PEA e longa carreira como musicoterapeuta desta associação.

O estudo de caso é um instrumento primordial na medida em que se debruça sobre uma situação específica procurando descobrir o que há de essencial e característico no indivíduo contribuindo para a compreensão de um ponto de interesse (PONTE, 2006; AZEVEDO, 2012).

\subsection{Instrumentos e Procedimentos}

A aplicação dos instrumentos antecedeu um pedido de autorização aos órgãos diretivos do Agrupamento de Escolas de Vilela, Paredes, onde se explica a natureza e interesse do estudo de caso e um pedido de consentimento informado à docente titular de turma e docente de educação especial, um pedido de consentimento informado aos pais do aluno, ao musicoterapeuta da UEE e ao musicoterapeuta da APPDA-Norte, referindo que se destinava a uma investigação no âmbito de um estudo.

Após deferimento do pedido e cumpridos os requisitos prévios, decorreu a recolha de dados qualitativos para este estudo empírico.

Os instrumentos utilizados nesta investigação para a recolha de dados foram a entrevista aos pais e entrevista ao musicoterapeuta da APPDA-Norte e a observação direta de uma criança do primeiro ciclo com PEA com registo da observação das sessões numa grelha de observação.

"O recurso a estes instrumentos de recolha de informação possibilita ao investigador qualitativo um contato direto e aprofundado com os participantes" (FERNANDES, 2017, p. 44).

O estudo pretendido teve início com a realização de uma entrevista aplicada aos pais, no sentido de conhecer a criança, a sua opinião sobre a importância da musicoterapia no tratamento do seu filho, assim como a sua opinião e expectativas em relação a esta terapia e uma entrevista ao musicoterapeuta da APPDA-Norte de modo a aferir qual a sua percepção acerca do tema e dos benefícios terapêuticos desta intervenção.

Atendendo à natureza estruturada da entrevista, as questões foram colocadas aos entrevistados garantindo a sua participação de forma voluntária e confidencial, 
respeitando a ética em investigação (PRADA; GARRIDO, 2013). A informação resultante das entrevistas foi transcrita na integra e para cada entrevistado (E), foi atribuído um código numérico: E1 e E2, de modo a salvaguardar a confidencialidade dos entrevistados. Os dados foram analisados com recurso à análise qualitativa de conteúdo categorial (HENRIQUES, 2014).

As sessões de musicoterapia decorreram numa sala criada para o efeito e tornada num espaço de grande empatia e conforto para o aluno, dispondo de todo o material necessário à realização desta atividade e sem a presença de elementos perturbadores. Foi tido em especial atenção o envolvimento pessoal numa tentativa de criar um ambiente de trabalho descontraído e informal para observar os efeitos que a musicoterapia transmite às crianças e a sua interação com a música e o musicoterapeuta e registada numa grelha de observação, constituída por alguns itens com o intuito de atender a elementos de carácter musical qualitativo avaliando a comunicação verbal e não verbal, os aspetos musicais, a utilização dos instrumentos e as competências cognitivas. Esta grelha de observação foi constituída por itens que foram classificados em conformidade com o comportamento observado na criança.

\section{Resultados}

A análise de conteúdo categorial permitiu identificar cinco categorias e treze subcategorias. A primeira categoria, comunicação, divide-se em duas subcategorias, interação/socialização e espontaneidade da interação/socialização. A segunda categoria, atividades, divide-se em duas subcategorias, envolvimento e interesse nas atividades e dificuldades sentidas, a terceira categoria, intervenientes, divide-se em duas subcategorias, contributo da família no processo educativo e contributo da equipa multidisciplinar, a quarta categoria, musicoterapia, divide-se em quatro subcategorias, fase indicada para iniciar/destinatários, conteúdos, expetativas e efeitos da musicoterapia, a quinta categoria, função terapêutica, divide-se em três subcategorias, mudanças, contributo para a saúde e bem-estar e desenvolvimento cognitivo, conforme Figura 1 e Quadro 1.

Figura 1 - Esquematização de categorias e subcategorias derivadas da análise de conteúdo categorial

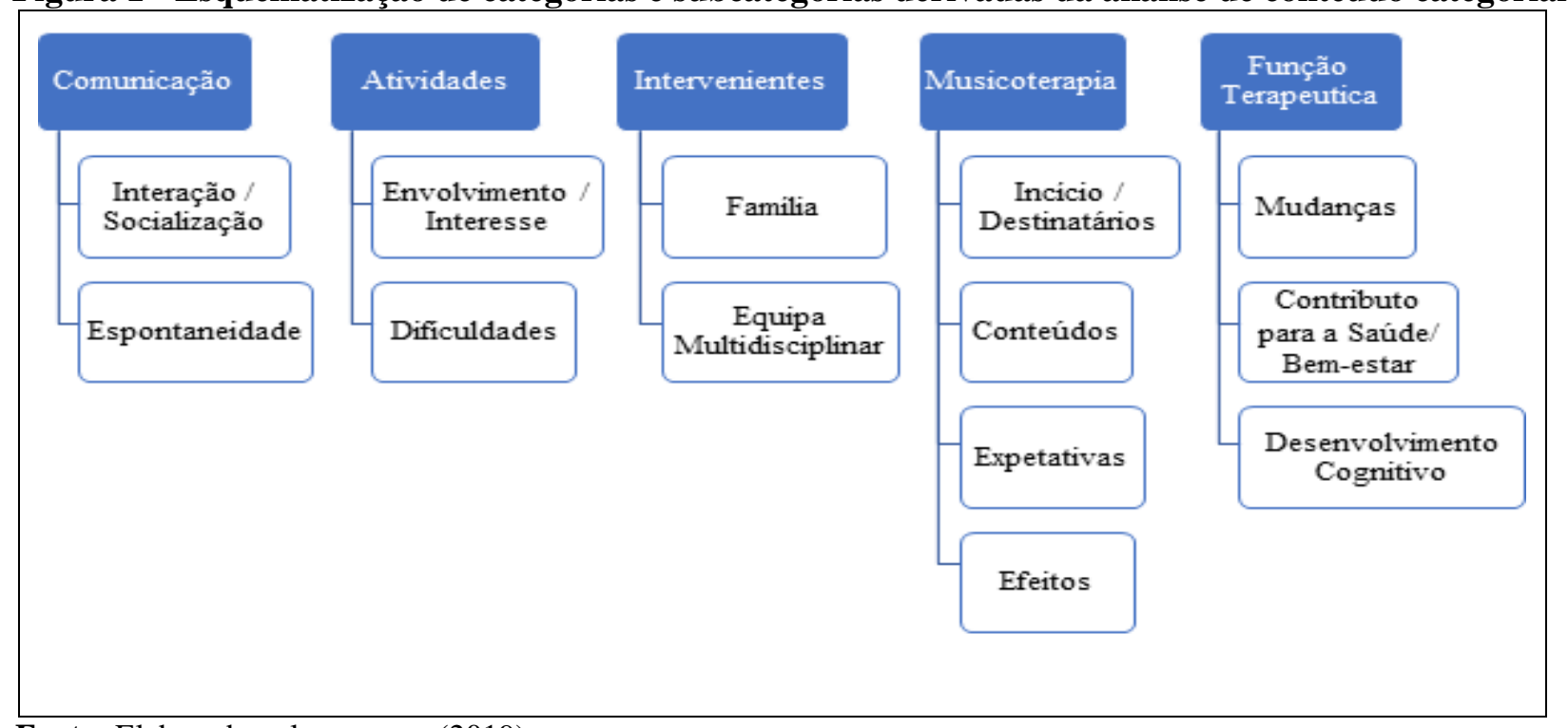

Fonte: Elaborado pelas autoras (2019). 


\section{Quadro 1 - Categorias e subcategorias identificadas com base na análise de conteúdo categorial}

CATEGORIAS SUBCATEGORIAS

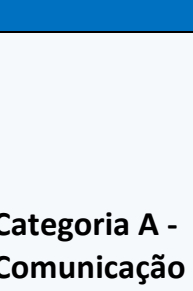

Comunicação

Atividades Intervenientes

Categoria D Musicoterapia

Categoria E -

Função

Terapêutica
Subcategoria A1 -

Interação/socialização

Subcategoria A2 -

Espontaneidade da interação/socialização

Subcategoria B1 Envolvimento e interesse

Subcategoria B2 -

Dificuldades sentidas

\section{EXEMPLOS}

"O A. tem linguagem verbal, para comunicar (...) aborda-nos fisicamente. Quando quer alguma coisa aponta para ela (...) praticamente só comunica por gestos (...) sabe comunicar usando alguma linguagem gestual (...) a sua grande conquista foi dizer o "dá" (...) já fez melhorias significativas." (E1)

"A música é linguagem, é o suporte do resto (...). Toda agente fala música (...). (E2)

“(...) o A. gosta muito de bebés, mas também interage com os adultos (...) procura mais os adultos porque já percebeu que estes (...) se esforçam mais para o perceber." (E1)

“(...) vou passear com ele no exterior e fazer atividades ao ar livre (...) gosta muito de jogos no tablet ou no telemóvel (...) ver televisão é a conquista mais recente. (...) também gosta de andar de patins e de bicicleta." (E1)

"A maior dificuldade é sem dúvida a comunicação, é a comunicação de coisas mais abstratas. (...) Ele tem muita dificuldade em expressar sentimentos. (...) por vezes chora ou grita." (E1)

Subcategoria C1 -

Contributo da família "Nós nunca desistimos do A., é uma luta constante. (E1)

no processo

educativo

Subcategoria C2 -

Contributo da equipa

multidisciplinar

"Há colaboração (...). Eles conseguiram a integração do meu filho no grupo e na sala de aula. Sempre que acontece alguma situação (...) sou comunicada. (E1)

Subcategoria D1 -

Fase indicada para iniciar/destinatários

“(...) quanto mais estimulação se der à criança melhor e quanto mais cedo melhor (...). Toda a gente fala música (...). Há que partilhar esse canal, essa linguagem (...) (E2).

A música vista de uma forma terapêutica também devia estar presente (...) tenho de aprender a comunicar com os sons, os meus sons e ouvir os sons do

Subcategoria D2 -

Conteúdos

A. e vamos aqui tentar encontrar uma cantiga (...) partilhar uma linguagem sonora. É para todas (...) para aquele menino autista deve vir em doses redobradas." (E2)

Subcategoria D3 - $\quad$ "Concentração, atenção, no autismo a concentração é muito importante,

Expetativas sobretudo no visualizar, (...) trabalhamos estereotipias (com o Sound Bean), (...) orientação espacial, coordenação motora, (...) fazemos uma aprendizagem bilateral, eu aprendo com eles e eles comigo. (...) O mundo dos sons, em termos de frequências é o "Abre-te Sésamo". (...) cada criança cria empatia com um instrumento." (E2)

Subcategoria D4 - $\quad$ "A música sempre o acalmou, ajuda-o a relaxar (...) a música faz milagres no A.,

Efeitos da

Musicoterapia espero que esta terapia o ajude." (E1)

“(...) era um jovem com NEE ter um aparelho (...) onde vai buscar a sua música, a sua matriz sonora (...) de forma a que ele relaxe." (E2)

Subcategoria E1 Mudanças

“(...) vamos ter um envolvimento cada vez maior na área da música, na

Subcategoria E2 Contributo para a saúde e bem-estar imaginação, na comunicação, todo o organismo vai mexer. A música é comunicação. (...) nas crianças com PEA (...) vai provocar-lhes um sentimento de querer mais e manifestam-se em termos de comunicação verbal ou não verbal (...). Por isso a música é tão importante. (...) é transversal a todas as áreas." (E2) 


\begin{tabular}{|c|c|c|}
\hline $\begin{array}{l}\text { Categoria E - } \\
\text { Função } \\
\text { Terapêutica }\end{array}$ & $\begin{array}{l}\text { Subcategoria E2 - } \\
\text { Contributo para a } \\
\text { saúde e bem-estar }\end{array}$ & $\begin{array}{l}\text { “(...) que a música o ajude na autorregulação das suas emoções.” (E1) } \\
\text { “(...) vão mostrando empatia por determinado instrumento ou atividade e vão } \\
\text { estabelecendo canais de comunicação, vão interagir comigo." (E2) } \\
\text { “(...) ouve a música que gosta e fica mais animada, estamos a intervir no seu } \\
\text { estado de espírito, saúde e bem-estar. Todos nós temos uma matriz que nos } \\
\text { guia (...). A música mexe conosco, é capaz de nos levar a extremos. (...) tudo o } \\
\text { que é música mexe com o organismo e regula ou desregula conforme o que } \\
\text { temos de matriz." (E2). }\end{array}$ \\
\hline & $\begin{array}{l}\text { Subcategoria E3 - } \\
\text { Desenvolvimento } \\
\text { cognitivo }\end{array}$ & $\begin{array}{l}\text { "Claro que sim. O jogo sonoro, do cubo mágico é exemplo disso (...) alguma } \\
\text { coisa nele pensou, experimentou e viu que funcionava." (E2) }\end{array}$ \\
\hline
\end{tabular}

Fonte: Elaborado pelas autoras (2019).

No que se refere a categoria Comunicação com os adultos/pares, os entrevistados forneceram respostas que nos permitem afirmar que a música é comunicação e que contribui para a interação e socialização favorecendo a espontaneidade da interação entre interlocutores. Relativamente à categoria, atividades e atendendo à análise da entrevista podemos aferir que são de extrema relevância para o desenvolvimento da criança em estudo, visto que a entrevistada demonstrou conhecimento das áreas em défice e as atividades capazes de promover melhorias. Na categoria intervenientes, verificou-se que a família, em articulação com a equipe multidisciplinar que participa no processo educativo têm realizado conquistas muito significativas no sentido de integrar a criança no seio familiar, escolar e social. Relativamente à categoria musicoterapia, constatamos que esta produz efeitos significativos na vida da criança, sobretudo em crianças com PEA ("nessas deve vir em doses redobradas", E2), pois a música produz um efeito muito positivo no sujeito observado ("a música faz milagres no A.", E1) e deve estar presente de forma terapêutica na vida de todos o mais precoce possível ("a música tem de lá estar desde sempre", E2).

Nas sessões de musicoterapia são trabalhadas as estereotipias, a atenção e a concentração (saber ouvir e expressar-se), orientação espacial e coordenação motora. "O mundo dos sons é o 'Abre-te Sésamo'" (E2) em que a aprendizagem é bilateral. Os entrevistados referiram ainda que é importante criar expetativas que ajudem o sujeito a relaxar e que o ajudem na autorregulação das suas emoções de modo a que esta terapia possa produzir efeitos ao nível da comunicação, socialização e imaginação. A música é tão importante porque é "transversal a todas as áreas" (E2) "Toda a gente fala música" (E2). Na categoria, função terapêutica, foram unânimes ao concluir que a música enquanto terapia produz mudanças significativas na vida dos sujeitos, nomeadamente a forma de comunicar ("vão estabelecendo canais de comunicação", E2) e que contribui para a saúde e bem-estar ( "A música mexe connosco, é capaz de nos levar a extremos.", E2) e para o desenvolvimento cognitivo na medida em que oferece estímulos motores, sensoriais, emocionais e cognitivos ("Alguma coisa nele pensou...", E2). 


\section{Análise da observação direta das sessões de musicoterapia}

A observação das sessões de musicoterapia decorreram entre o dia 25 de janeiro e 23 de fevereiro de 2018, perfazendo um total de dez sessões com a duração de sessenta minutos, seguindo uma estrutura que se baseava na utilização de instrumentos musicais, cantar canções com coreografia e dança e relaxamento, as sessões foram avaliadas com base na interpretação qualitativa por observação direta em contexto de sessão com registo numa grelha de observação que avalia a comunicação verbal e não verbal, os aspetos musicais, utilização dos instrumentos e as competências cognitivas.

Como podemos verificar na grelha de observação, o A., não estabeleceu comunicação verbal em nenhuma das sessões observadas, porém ao nível da linguagem não verbal é visível o seu interesse gradual pelas atividades, o A. passou a expressar-se corporalmente com intensão e estabeleceu contato ocular com o musicoterapeuta e com os pares abrindo "caminho" para a interação e socialização, a nível musical foi capaz de fazer exploração sonora e criar ritmo e melodia expressando os seus estados de espírito e fomentando a comunicação e imaginação através do diálogo musical improvisado. Apesar de não possuir linguagem verbal, o A. foi capaz, através da produção de alguns sons vocálicos expressar-se de forma musical com intensão. Ao longo das sessões foi ainda notório o seu envolvimento com os pares na partilha e exploração dos instrumentos musicais. A nível cognitivo também foram observadas melhorias significativas, foi capaz de identificar os instrumentos, memorizar sequências rítmicas/melódicas manifestando interesse e concentração.

Em suma, é pertinente referir que esta terapia foi eficaz e benéfica na medida em que foram observados progressos e melhorias ao nível da comunicação, socialização e imaginação do aluno em estudo. A estrutura das sessões e o fato de serem realizadas em grupo permitiu a interação entre o aluno e os pares favorecendo a comunicação e socialização evitando o isolamento.

\section{Discussões e considerações finais}

Este estudo teve como propósito aferir os efeitos que a musicoterapia é capaz de produzir em crianças com PEA na comunicação, na socialização e na imaginação através da utilização dos seus elementos: som, ritmo, melodia e harmonia (FRAGA, ALLGAYER; KRUG, 2017)

Os resultados indicam que a música traz benefícios a nível terapêutico e que deve iniciar-se o mais precoce possível para as crianças portadoras de PEA, pois um diagnóstico precoce possibilita melhorias significativas (FPDA, 2017) e deve envolver todos os intervenientes no processo, família, escola e terapeutas, de modo a promover o desenvolvimento da criança ao nível da comunicação, socialização e imaginação.

A música assume um papel importante na educação na medida em que surge como a porta de entrada para o mundo autista (HERDY; CARMO, 2016) e ajuda a estabelecer canais de comunicação com crianças que através das vias tradicionais não o fazem ou revelam dificuldades significativas, nomeadamente crianças com PEA, cuja comunicação é uma incapacidade visível que afeta todo o seu desenvolvimento. 
A música é vista, neste estudo, como uma terapia que facilita o enriquecimento pessoal, social e cultural da criança. Pelo que foi referido, é pertinente perceber a musicoterapia como uma ciência enraizada na nossa natureza, pertencente ao ser humano desde as suas origens, toda a gente fala música, é através dela que o indivíduo se encontra consigo próprio e com o mundo que o rodeia, a música contribui para a identidade cultural de cada um de nós, a música é harmonia e equilíbrio (MATOSO; OLIVEIRA, 2017).

A música como terapia é comunicação e promove a interação e socialização dos indivíduos que nela participam de forma natural e espontânea, proporcionando momentos de libertação e criação espontânea e permitindo a abertura de um novo canal de comunicação entre o musicoterapeuta, a criança e o mundo que a rodeia. A música é considerada uma arte e permite que a criança brinque com os sons e ritmos (FERREIRA, 2012), potenciando novas formas de experimentar e desenvolver a criatividade e a imaginação. Ao falar de música falamos de uma linguagem universal (MONTEIRO, 2016), capaz de transpor barreiras culturais, cognitivas e emocionais.

As atividades devem ser desenvolvidas por um técnico qualificado, o musicoterapeuta, que numa fase inicial deve permitir que a criança se sinta bem e efetue a ambientação ao espaço, explorando todas as suas potencialidades e descobrindo o seu ponto de interesse. As sessões devem primar pelo envolvimento e interesse da criança atenuando as barreiras da comunicação e socialização. Devem permitir que a criança explore todos os meios ao seu alcance para comunicar e interagir. Devem promover a comunicação e interação entre terapeuta e criança de forma acolhedora e humanizada (FREITAS et al., 2017) e promover a criatividade e espontaneidade (DE VRIES, 2015).

Com base na análise das entrevistas e da observação direta, podemos ainda afirmar que esta terapia, quando realizada em pequeno grupo produz efeitos significativos ao nível da comunicação e socialização entre pares visto que atenua o isolamento destas crianças e Ihes proporciona a oportunidade de vivenciar experiências comuns, a prática musical em grupo é um fator de acesso à comunicação entre pessoas (FERNANDES, 2017).

Nas sessões promove-se a concentração, a atenção, a interação, a comunicação e socialização, há espaço para a criança desenvolver a imaginação $p$ do jogo sonoro, da improvisação, da criação pessoal ao gosto de cada um em particular. Através dos sons, a criança é capaz de se expressar, de se movimentar, dançar e imaginar. A capacidade inata de responder a estímulos musicais permite comunicar usando a música como forma de expressão e dos sons musicais (MONTEIRO 2016).

Da análise dos dados verificou-se ainda que cada sessão de musicoterapia se transforma num momento importantíssimo de descoberta para as crianças e para o musicoterapeuta, onde a forma natural e espontânea de interagir revelaram ser de extrema importância para melhor conhecer o indivíduo e aprender a comunicar e interagir. A principal atividade levada a cabo durante as sessões de musicoterapia foi a improvisação, permitindo que os indivíduos se manifestassem de forma intuitiva, revelando a sua predisposição para estar na sessão e permitindo estabelecer uma relação terapêutica baseada na comunicação e interação musical onde cada um tinha a oportunidade de manifestar as suas emoções, sonhos, fantasias e memórias através da música (MONTEIRO, 2016).

Vários estudos revelam que esta terapia é fundamental na medida em que promove mudanças a nível comportamental contribuindo para a autonomia e 
autoestima da criança, pois ao ouvir a música que gosta, a música que se identifica com a sua matriz sonora, vai tornar-se mais confiante e segura na tomada de decisões e na prática das suas ações diárias, através da música vai encontrar refúgio para as suas frustrações e vai descomprimir a pressão e ansiedade (MONTEIRO, 2016), vai permitir a abertura de um novo canal de comunicação (HERDY; CARMO, 2016).

Neste estudo, a musicoterapia é, igualmente importante, permitindo estímulos motores, sensoriais, emocionais e cognitivos e promovendo a maior consciencialização corporal resultando em melhorias na orientação espacial, coordenação motora e desenvolvimento intelectual. A musicoterapia permite que seja aberto um novo canal de comunicação onde há entendimento das emoções, em que se aprende a ouvir, a expressar-se através dos sons e dos movimentos. Permite trabalhar estereotipias, onde a criação musical atenua estes comportamentos involuntários.

É ainda crucial que as expetativas do musicoterapeuta se enquadrem, valorizando os progressos alcançados por estas crianças e aceitando os seus ritmos de aprendizagem e formas muito próprias de aderir à estrutura das sessões, em suma, é importante que as expetativas sejam positivas e adequadas a cada criança atendendo às suas características e ao seu contexto.

Torna-se, portanto, essencial que os profissionais da educação e os demais intervenientes no processo educativo de crianças com PEA tenham uma conceptualização uniformizada sobre esta temática de forma a que esta passe a fazer parte integrante na vida das crianças com PEA, reforçando os seus efeitos e benefícios na comunicação, socialização e imaginação, assim como na regulação de estereotipias e desenvolvimento de competências.

Uma vez enunciadas as conclusões finais, estamos em condições de proferir as ilações que dela surgem, em termos de delineação do processo de investigação e sugestão de novas propostas para estudos futuros sobre esta temática.

Ao longo deste estudo, destacamos como principal limitação o tempo de observação para recolha de dados, salientando que a permanência de mais tempo de observação iria permitir uma conclusão mais sólida dos resultados.

Para a realização de investigações futuras seria pertinente estudar idades mais precoces de modo a analisar os benefícios que esta terapia trará nestas idades alertando para a necessidade de ser implantada nas escolas como terapia complementar no tratamento de crianças com PEA. No futuro seria ainda pertinente dar ênfase à necessidade de formar profissionais na área da musicoterapia de forma a permitir que esta passe a fazer parte das estratégias a desenvolver no sentido de produzir melhorias na qualidade de vida das crianças com PEA.

\section{REFERÊNCIAS}

AZEVEDO, Juliana Celina Janela. A aplicação da musicoterapia numa criança com espectro do autismo: estudo de caso. 2012. 96 f. Dissertação (Mestrado em Ciências da Educação - Educação Especial) Universidade Católica Portuguesa, Braga, Portugal, 2012. 
BRUSCIA, Kenneth E. Improvisational models of music therapy. Springfield: Charles C. Thomas Publications, 2000.

BUNT, Leslie; STIEGE, Brynjulf. Music therapy, an art beyond words. Second Edition. published by Routledge - Sussex, Great Britain e by Routledge, New York, USA. Printed and bound in Great Britain by TJ International Ldt, Padstow, Cornwall, 2014.

CASTRO, Maria Teresa de Lara Arriaga. Afinar a relação: a musicoterapia e a perturbação no espetro do autismo. 2016. 83 f. Dissertação (Mestrado em Musicoterapia) Universidade Lusíada de Lisboa, Lisboa, Portugal. 2016.

CUNHA, Rosemyriam; ARRUDA, Mariana; SILVA, Stela Maris da. Homem, música e musicoterapia. Incantare - Revista do Núcleo de Estudos e Pesquisas

Interdisciplinares em Musicoterapia, Curitiba, v. 1, p. 1-26, 2010. Disponível em: http://periodicos.unespar.edu.br/index.php/incantare/article/view/168 Acesso em: 24 jun. 2019.

DE VRIES, Dawn et al. Music as a therapeutic intervention with autism: a systematic review of the literature. Therapeutic Recreation Journal, v. XLIX, p. 220-237, 2015.

EREN, Bilgehan. The use of music interventions to improve social skills in adolescents with Autism Spectrum Disorder in integrated group music therapy sessions. Procedia - Social and Behavioral Sciences, v. 197, p. 207-213, 2015.

FERNANDES, Patrícia Raquel da Silva. Sons, silêncios: a importância da musicoterapia em pessoas com PEA. São Paulo: Novas Edições Acadêmicas, More Books. 2017.

FERREIRA, Isabel Maria Campos. A importância da música no desenvolvimento global das crianças com Necessidades Educativas Especiais: Perspetiva dos Professores do 1.0 Ciclo e de Educação Especial. 2012. 87 f. Dissertação (Mestrado em Ciências da Educação na Especialidade em Domínio Cognitivo e Motor). Escola Superior de Educação João de Deus, Lisboa, Portugal, 2012.

FOLGADO, Sílvia Branco. A comunicação e a interação na criança autista: um estudo de caso. 2013. 295 f. Dissertação (Mestrado em Ciências da Educação na Especialidade em Domínio Cognitivo e Motor). Instituto Politécnico de Castelo Branco, Castelo Branco, Portugal, 2013.

FRAGA, Itamar Micail Santana; ALLGAYER, Manuela Filter; KRUG, Suzane Beatriz Frantz. A arte da musicoterapia: uma revisão narrativa. In: IV Seminário Científico do Programa de pós-Graduação em Promoção da Saúde. Anais... Santa Cruz do Sul RS, UNISC, 2017.

FREITAS, Laura Rabelo; GUIMARÃES, Camila Santos; USTCH, Paulla Rayane Chaves; SOARES, Gastão Luis Fonseca; NETO, Carmine Martuscello. Musicoterapia: 
Alicerce à terapêutica e estratégia de atendimento humanizado. Revista de Saúde, v. 8, n. 1, p. 116-117, 2017.

HENRIQUES, Susana. Análise de Conteúdo: iniciação à investigação educacional licenciatura em educação. Lisboa, Portugal: Universidade Aberta, 2014.

HERDY, Alessandra; CARMO, Carolina. Os Efeitos da Musicoterapia em Pacientes Portadores do Transtorno do Espectro Autista. Revista interdisciplinar do pensamento Científico, Journal os Music Therapy, v. 2, n. 2, p. 283-341, 2016.

KIM, Jinah; WIGRAM, Tony; GOLD, Christian. Emotional, motivational and interpersonal responsiveness of children with autism in improvisational music Therapy. Autismo, v. 1, n. 4, p. 389-409, 2009.

MATOSO, Leonardo; OLIVEIRA, Agostina. O efeito da Música na Saúde Humana: Base e Evidências Científicas. Revista Ciência e Desenvolvimento, v. 10, n. 2, p. 76-98, 2017.

MONTEIRO, Raquel Sofia Carvalho. A musicoterapia em contexto escolar: perturbações do comportamento, espectro do autismo e multideficiência. 2016. 50 f. Dissertação (Mestrado em Musicoterapia), Universidade Lusíada de Lisboa, Lisboa, Portugal. 2016.

PLIMLEY, Lynn; BOWEN, Maggie; MORGAN, Hugh. Autistic Spectrum Disorders in the Early Years. Ebook Kindle, Sage Publications, 2007.

PONTE, João Pedro. Estudos de caso em educação matemática. Bolema, v. 25, p. $105-132,2006$.

PRADA, Marília; GARRIDO, Margarida Vaz. Conhecer as regras do jogo: Uma introdução às normas para a escrita científica da American Psychological Association. Psicologia, v. 27, n. 2, p. 107-143, 2013.

SAMPAIO, Renato Tocantins; LOUREIRO, Cybelle Maria Veiga; GOMES, Cristiano Mauro Assis. A Musicoterapia e o Transtorno do Espectro do Autismo: uma abordagem informada pelas neurociências para a prática clínica. Per Musi, Belo Horizonte, n. 32, p. 137-170, dez. 2015

SIMPSON, Kathryn Mary. The use of Musical Elements to Influence the Learning of Receptive Communication skills in children with autism. 2013. 292 f. Tese (Doutorado em Filosofia). Australian Catholic University, 2013.

RUUD, Even. Caminhos da Musicoterapia. São Paulo: Editora Afiliada, 1990.

WHEELER, Barbara. Developments in Music Therapy Practice: Case Study Perspectives. Journal os Music Therapy, v. 49, p. 365-369, 2012. 
WIGRAM, Tony; PEDERSEN, Inge Nygaard. A Comprehensive Guide to Music Therapy: Theory, Clinical Practice, Research, and Training. Los Angeles: Jessica Kingsley Publishers, 2002.

WOLD FEDERATION OF MUSIC THERAPY. History. 2008. Disponível em: http://www.wfmt. info/WFMT/about_WFMT_files/WFMT\%2 OHistory_7-08.pdf. Acesso em: 24 jun. 2019. Aceito em: 03 de dezembro de 2020. Publicado em: 05 de janeiro de 2021. 